\title{
Technology Trend Study Based on Valid Patents of Smartphone Industry
}

\author{
Mier Zhang, Haipeng Li, and Ximei Liu
}

\begin{abstract}
Technology trend study is crucial to new product development. In the past decade, smartphones were star products. However, a ceiling effect emerged in the field of smartphone industry. A new generation of smartphone is similar to the previous generation. It has become an urgent task to analyze the technology trend of smartphone industry, thus finding development direction in the future. The patent data are retrieved in the emerging patent database. Based on valid patents, the technology trend is analyzed by hierarchical clustering analysis. The result of time series analysis shows that low power design of smartphones went through the germination period, outbreak period, and rapid growth period, and is in the sustainable growth period at present. In the foreseeable future, low power design will still be in the sustainable growth period. Thus, low power design could be one of the important directions for smartphone industry.
\end{abstract}

Index Terms-Clustering analysis, technology trend, time series, valid patent.

\section{INTRODUCTION}

Technology trend study has been increasingly important in new product development. The capability of keeping ahead of new technologies and monitoring technology trend is of great importance. Smartphones are getting more and more sophisticated in the past decade. However, in recent years, a ceiling effect has emerged in the field of smartphone industry. A new generation of smartphones is very similar to the previous generation products. What is the development direction in the future? Smartphones emerged around 2000. Smartphones sales worldwide have been steadily growing from 2008 [1]. According to the International Data Corporation, worldwide smartphone shipments declined $0.5 \%$ in 2017 . The market has experienced a first persistent decline since the introduction of what we now know as smartphones [2]. Smartphones become more functional but the duration is still a short board. It is difficult to meet the needs of consumers. Hence, it is necessary to study the development direction for smartphone industry.

With the rapid development of innovative applications for smartphones, low power design has become one of the most important technologies. More innovative applications have appeared, including programs and applications [3]. Real-time location-based tracking applications require continuous GPS calculations and transmissions, which consume a

Manuscript received March 30, 2019; revised June 22, 2019. This work was supported by the National Natural Science Foundation of China (71572024 and 71834006)

Mier Zhang, Haipeng Li, and Ximei Liu are with School of Economics and Management, Dalian University of Technology, Dalian, China (e-mail: ZHMILL@dlut.edu.cn). considerable amount of the phone's battery [4]. The growing popularity of mobile internet services, characterized by heavy network transmission, intensive computation, and an always-on display, poses a great challenge to the battery lifetime of mobile devices [5]. Location based services have rapidly developed as important added features, but one of the challenges is mobile power consumption [6].

Advances in low power design have not kept pace with rapidly growing energy demands [7]. From stock tickers to citywide social games, these devices promise to offer support for a large spectrum of applications [8]. Most smartphones use rechargeable electrochemical batteries, typically, lithium-ion batteries, as their portable energy source. These fully charged batteries can run on this charge for only a few hours. Therefore, the power consumption has emerged as the key issue of the energy management for portables [9]. Spectacular advances in hardware and software technologies have resulted in powerful mobile devices. However, the rapid evolution in hardware and software capabilities has not been paralleled a similar advance in battery technology [10]. Therefore, the issue of managing power consumption in multicore smartphones is of paramount importance [11].

As the strategic importance of understanding changes in technology for successful business of most firms' increases, the ability to analyze and monitor the current stage and history of technology is reckoned as a critical asset for gaining competitive advantage and promising niches [12]. Among the numerous technology-forecasting indicators, patent is a mature and objective indicator [13]. Patent information records problems and solutions of specific technical fields. Patent analysis is an effective tool for researching the trend of technology development. Prediction of benefits from investment in a new technology is of great interest [14]. Forecasting the future technology is important for the decision makers. Patent data are used to predict technology trend when analyzing technology life cycle, diffusion potential, and technology scope [15].

The International Patent Classification (IPC) is an internationally recognized patent classification system, which can reflect the technology field of patents. The convergence process of technology fusion toward the launch of new products is analyzed by IPC co-occurrence based on cutting-edge technologies [16]. IPC codes from the patent documents of a target technology are used to construct an emerging technology-forecasting model, which combines statistical inference and neural networks for new patent information analysis [17]. The number of IPC codes represents how many fields are involved in the development of a technology, which can be an indicator to estimate the future development of one technology and make decisions 
whether to invest in it or not [18].

Patent documents contain important research results that are valuable to industry, business, law, and policy-making communities [19]. Patent text-based technology evolution analysis refers to the use of patent text, through manual reading or text mining technology to carry out technology evolution analysis. The technological S-curve is predicted by integrating bibliometric and patent analysis into the logistic growth curve model based on co-word analysis [20]. Patent documents are ample source of technical and commercial knowledge and, thus, a network-based analysis is proposed to provide richer information and enable deeper analysis since it considers more keywords and produces more indexes. These visuals and indexes can be used to analyze up-to-date trends of high technologies and identify promising avenues for new product development [21]. A data-mining approach is proposed by weighted association rule based on algorithms for the analysis of relationships among different technologies, which may result in technology maximizing profits [22]. Smartphones become more and more functional, but the duration of smartphones is still a short board. Will low power design be a direction for smartphones in the future?

\section{Methodology}

\section{A. Research Design}

This study aims to study the technology trend for smartphone industry based on valid patents. On this basis, hierarchical clustering analysis is employed to classify the technology trend. To analyze the technology trend quantitatively, appropriate quantitative index will be selected Patent application and grant indexes are used frequently in existing studies. However, a patent has a certain life span, and the invalidation of a patent is often ignored. The longer the patent is maintained, the higher the patent value is [23]. Patents with large patents family have a relatively long duration and a great role in sustained innovation [24]. To assess the factors affecting the duration of a pharmaceutical patent, it is necessary to analyze the published patent information data and market information [25]. The degree of commercialization of patented technology is very important for patent maintenance decisions [26]. The value of patents granted by the European Patent Office is much higher than that of patents granted by its member states, and the duration of patents granted by the European Patent Office is correspondingly longer [27].

After being granted by the state department, a patent becomes valid. Afterwards, there are many influence factors, such as abandonment of rights, invalidation and expiration of protection period, which lead to the invalidation of a patent. Due to invalid patents, there are great differences between valid patents and patent application and grant. Therefore, valid patents are selected as the quantitative index. Valid patents not only reflect the life span of patents, but also reflect patent stock, which can quantitatively research the technology trend. However, the number of valid patents cannot be obtained directly from the patent database. It is necessary to rely on existing patent information to construct a quantitative method to calculate the number of valid patents.
With the development of patent databases in recent years, it is possible to calculate the number of valid patents efficiently.

Therefore, based on the emerging patent databases and patent analysis tools in recent years, valid patents are taken as a breakthrough for the research. By analyzing and calculating massive patents, the quantitative method of calculating the number of valid patents is constructed. On this basis, hierarchical clustering analysis is employed to classify the technology trend. Based on the time series data, the technology trend is classified into different periods. In addition, the features and differences of each period are analyzed, which reveals dynamic technology trend.

\section{B. Measurement Index}

To analyze the technology trend quantitatively, the quantitative index of patents needs to be selected. A patent has a certain life span that begins from the grant day to the invalidation day. A valid patent is a patent for the maintenance of the patent right. Patent rights are maintained by paying annual fees until the patent expired. The patentee filed a patent application and became a valid patent after being granted by the state department. Since then, valid patent expired due to various reasons, such as giving up rights, declaration of avoidance, and expiration of the protection period. Therefore, it is necessary to construct the quantitative method to calculate the number of valid patents to analyze the time series data.

However, the number of valid patents cannot be obtained directly from the patent database. It is necessary to rely on existing patent information and patent analysis tools. The number of valid patents is dynamically changing, patent grant increases valid patents, invalid patents reduce valid patents, and calculating their difference is the number of valid patents. In the patent documents of each country, the information related to valid patents can be extracted, such as the grant date and the legal status. The legal status is the legal information disclosed in the patent gazette, including the grant day, invalidation day, and termination of patent rights, and so on.

$$
P_{t}=\sum_{i=1}^{t}\left(G_{i}-E_{i}\right)
$$

In this formula, $\mathrm{P}_{\mathrm{t}}$ is the number of valid patents in year $\mathrm{t}$, $\mathrm{G}_{\mathrm{i}}$ is the number of patent grant in year $\mathrm{i}, \mathrm{E}_{\mathrm{i}}$ is the number of invalid patents in year $i$, and $t$ is the number of years from the start year to year t. Firstly, relying on the emerging patent analysis system, set search terms such as keywords, IPC, and grant date, and obtain patent grant data. Then, extract grant date and invalidation date of above-mentioned patents through the legal status, and calculate the number of invalid patents. Finally, according to the above formula, the difference between the number of patent grants and invalid patents over the past years is calculated and the number of valid patents is obtained.

\section{Trend Research Method}

Based on the above analysis, the number of valid patents is affected by the number of patent grants and invalid patents. According to the dynamic changes in the number of valid 
patents, the technology trend is a dynamic development process. Therefore, in order to reveal the dynamic development process of technology trend, it can be classified into different periods by valid patents quantitatively, and characteristics and differences between each period are analyzed. Then the development process of the technology trend is cleared to provide the management support.

In order to research the technology trend, the scientific method should be employed to classify the trend based on valid patents. The equalization method was used to classify patent applications of solar technology into four periods, and its evolution was analyzed [28]. This qualitative method has loose requirements for data analysis, and results are influenced by subjective factors easily. Word frequency analysis combines with patent applications to generate a patent network reflecting the evolution of technology [29]. However, this method requires strict data and the calculation process is complex. Therefore, hierarchical clustering analysis is employed to classify the technology trend. It is a quantitative analysis method, which can avoid the complex data processing.

Hierarchical clustering analysis is an objective method to process the classification of indicators. The samples are clustered based on the similarity and the relation. It was used to analyze features of subjects in patent litigations, and the classification of subjects was divided. At the same time, it is a common method to study the time series clustering [30]. It needs to select relevant data of the research object as clustering indicators, and the above time series data can provide basic data. As a common method, hierarchical clustering analysis is helpful to reduce the interference of subjective judgments on sample classification.

The technology trend can be classified by hierarchical clustering analysis. Using patent data as samples, the technology trend is classified by the similarity and the relation between samples. Firstly, appropriate clustering indicators are selected. Secondly, indicators data are imported into the computer system, and the closest samples are clustered into a small class based on the similarity and the relation between samples. Then, compared the similarity and the relation between other samples and the small class, the closest samples are clustered into a class. Finally, clustering process is end, and a tree diagram can be selected as the result form for objective analysis of clustering results.

The selection of appropriate clustering indicators is the key process of hierarchical clustering analysis. Firstly, the technology trend is a dynamic process, and its development status is different in each year. Therefore, the year data are determined as a cluster sample. Then, the number of valid patents is selected as the clustering indicator, because it can directly reflect the development trend of technology. Finally, the growth rate of valid patents is determined as the clustering indicator, because the growth rate can reflect the changing state of the number of valid patents. Based on the above analysis, the number of valid patents, its growth rate, and years are selected as clustering indicators. The technology trend can be classified to different periods, and the features and differences of each period are analyzed, which reveals the dynamic evolution of the technology.

\section{TEChNOLOGY TREND RESEARCH}

\section{A. Data Mining}

Smartphones are becoming more and more sophisticated but a ceiling effect has emerged in recent years. It is necessary to study which direction will be developed for smartphone industry. With the rapid development of innovative applications for smartphones, low power design becomes one of the important technologies. Will low power design be a direction for smartphone industry in the future? It is necessary to study on low power design by patent documents, to provide decision support for new product development.

TABLE I: CALCULATION TABLE OF VALID PATENTS

\begin{tabular}{|c|c|c|c|c|}
\hline Year & $\begin{array}{c}\text { Patent } \\
\text { application }\end{array}$ & $\begin{array}{c}\text { Patent } \\
\text { grant }\end{array}$ & $\begin{array}{l}\text { Invalid } \\
\text { patent }\end{array}$ & $\begin{array}{l}\text { Valid } \\
\text { patent }\end{array}$ \\
\hline 1985 & 4 & 0 & 0 & 0 \\
\hline 1986 & 6 & 0 & 0 & 0 \\
\hline 1987 & 4 & 0 & 0 & 0 \\
\hline 1988 & 4 & 1 & 0 & 1 \\
\hline 1989 & 8 & 1 & 0 & 2 \\
\hline 1990 & 12 & 8 & 0 & 10 \\
\hline 1991 & 2 & 6 & 1 & 15 \\
\hline 1992 & 15 & 9 & 1 & 23 \\
\hline 1993 & 41 & 1 & 3 & 21 \\
\hline 1994 & 85 & 10 & 0 & 31 \\
\hline 1995 & 169 & 5 & 1 & 35 \\
\hline 1996 & 203 & 7 & 1 & 41 \\
\hline 1997 & 350 & 9 & 4 & 46 \\
\hline 1998 & 375 & 7 & 3 & 50 \\
\hline 1999 & 460 & 15 & 4 & 61 \\
\hline 2000 & 637 & 27 & 5 & 83 \\
\hline 2001 & 823 & 73 & 4 & 152 \\
\hline 2002 & 1054 & 212 & 7 & 357 \\
\hline 2003 & 1589 & 455 & 16 & 796 \\
\hline 2004 & 1449 & 641 & 28 & 1409 \\
\hline 2005 & 1854 & 531 & 63 & 1877 \\
\hline 2006 & 2922 & 692 & 56 & 2513 \\
\hline 2007 & 3028 & 673 & 108 & 3078 \\
\hline 2008 & 2914 & 952 & 152 & 3878 \\
\hline 2009 & 2813 & 1267 & 178 & 4967 \\
\hline 2010 & 3304 & 966 & 184 & 5749 \\
\hline 2011 & 3724 & 1366 & 276 & 6839 \\
\hline 2012 & 4250 & 1799 & 237 & 8401 \\
\hline 2013 & 4296 & 1531 & 340 & 9592 \\
\hline 2014 & 3879 & 1368 & 400 & 10560 \\
\hline 2015 & 4468 & 2000 & 604 & 11956 \\
\hline 2016 & 4976 & 2707 & 699 & 13964 \\
\hline 2017 & 4788 & 2557 & 826 & 15695 \\
\hline
\end{tabular}


As a portable terminal, smartphones rely entirely on batteries to supply power. With the increasing function of smartphones, their power consumption is also increasing. Therefore, it is necessary to prolong standby time and using time of smartphones. There are two solutions to this problem. One is to equip mobile phone batteries with larger capacity, the other is to improve the system design and adopt advanced technology to reduce the power consumption of mobile phones. We need to start with the overall design of smartphones and adopt advanced technology and devices to reduce power consumption, to prolong standby time and using time of smartphones as long as possible. Through reading and analyzing the related literature of low power design technology of smartphones, the key words mainly include battery, low power, and energy reduce.

In recent years, new and emerging patent analysis system provides the possibility for analyzing patent accurately and quickly. As a new patent analysis system, Patsnap not only integrate patents of the patent office database around the world, but also has the function of statistical analysis and trend analysis. Due to the update delay of patents data, the deadline of patent grant date is set at December 31, 2017. The grant data of invention patent are retrieved. The data are formed the basis data to calculate the number of valid patents. The last updated date of the legal status is used to determine the time of the invalidation of patents and then calculate the number of invalid patents. Based on the above formula, the number of valid patents is calculated by the number of patent grant and invalid patents over the years in Table I.

The analysis of time series data shows that the number of patent applications and grants of Chinese low power design is increasing. In 1985, the patent system was implemented in China, and then patent applications of low power design began to appear. From 1988, the patent applications began to be granted, since then, the number of patent applications and grants maintain a growing trend. However, from 2006 to 2017 , the number of patent applications and grants appeared significant fluctuations. The validity of patents is affected by many factors after patent grant. These factors will lead to the invalidation of patents. From 1991, invalid patents began to appear, and since then, the number of invalid patents of low power design showed an increasing trend.

\section{B. Measurement Analysis}

The time series data show that there is a growing trend in the number of valid patents on Chinese low power design technology from the overall point of view. The number of valid patents has lagged behind patent applications since 1988. After years of accumulation, the number of valid patents exceeded 100 for the first time in 2001, and then followed by rapid growth in the following years. It is the first time that the number of valid patents exceeded 10000 in 2014 However, with the increasing of patent grants, the number of invalid patents also increased. Because of the common influence of patent grants and invalid patents, the growth rate of valid patents of low power design slowed down from 2002.

Fig. 1 displays that the number of patent grants are subject to greater volatility, but the number of valid patents shows a modest trend. There were little valid patents in the early period, and then it began to grow rapidly. The number of valid patents reflects the lack of low power design patents in the early phase, which experienced a process of rapid growth at first and then gradually slowing down the growth rate. Compared with patent applications and grants, the number of valid patents reflects the stock of patents and the development trend more objectively, which shows the rationality of selecting valid patents as the measurement index at the realistic level. The number of valid patents can show the development trend, but it cannot reveal the evolution and the features of each evolutionary period Therefore, it is necessary to analyze the evolution of low power design by valid patents.

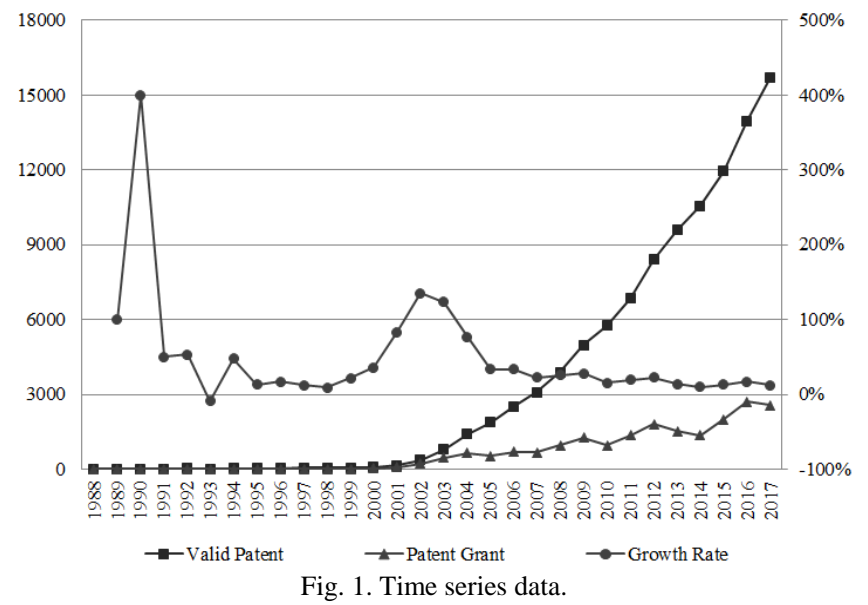

\section{Trend Analysis}

In order to study the evolution of the technology, the time series data need to be clustered by hierarchical clustering analysis, which can avoid being influenced by subjective factors as far as possible. The relevant data need to be selected as clustering indicators. According to the above analysis, the time series data of valid patents are taken as the clustering indicators, which include the number of valid patents and its growth rate. Then the above relevant data of the clustering indicators are imported into SPSS 19.0 and the system began to hierarchical clustering analysis. The SPSS system formed a tree diagram by hierarchical clustering analysis. Finally, classification distance is selected in the tree diagram to divide the technology trend of low power design in China into different periods.

In the tree diagram, the period classification is conducted by selecting the classification distance. If the classification distance is too long then the period classification will be too little, thus, it is hard to carry out the following research. On the contrary, if the classification distance is too short, the period classification will be too much, then losing the meaning of classification. Hence, the classification distance is set to 3 shown in Fig. 2. The technology trend is classified into four periods, 1988-2005 for period I, 2006-2011 for period II, 2012-2015 for period III, and 2016-2017 for period IV. Thus, the above periods have significant differences, and the indicators data in the same period has a strong cohesion, which achieved the purpose of quantitative period classification. 


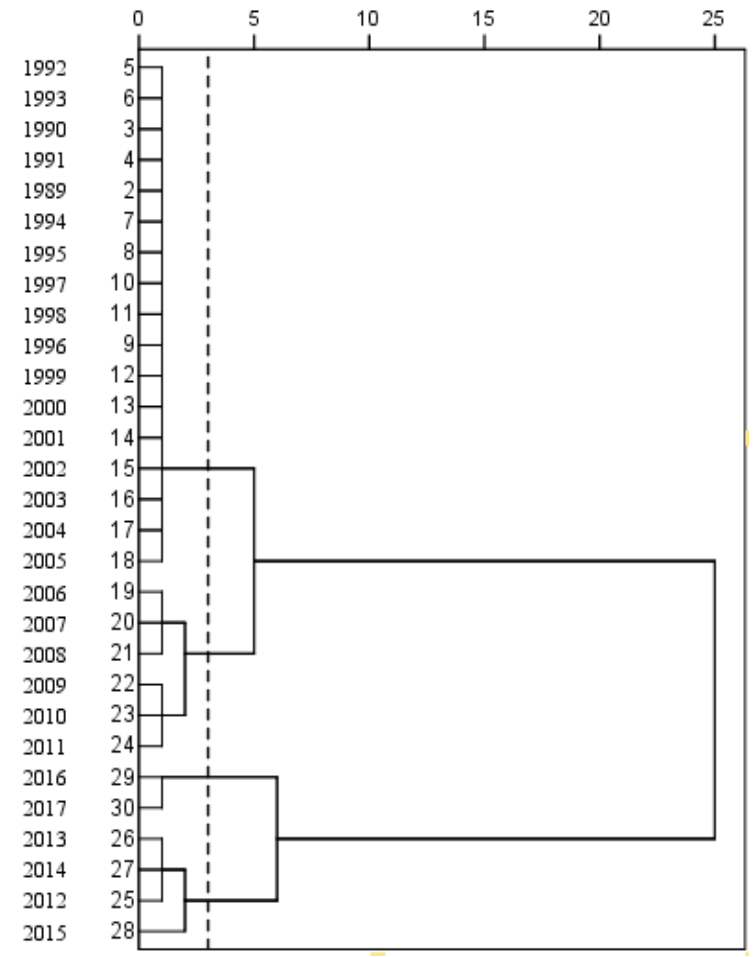

Fig. 2. Tree diagram for hierarchical clustering analysis.

The above clustering analysis shows that the technology trend of low power design has experienced four periods and each period presents different features, which are shown in Fig. 3. Period $I$ is the germination period, in which the number of valid patents is small. However, after a prolonged period development, the number of valid patents increases from 1 in 1988 to 1877 in 2005 . The second period is the outbreak period. Although the number of valid patents is still small, but the average growth rate of valid patents is $22.2 \%$, which shows the explosive growth trend.

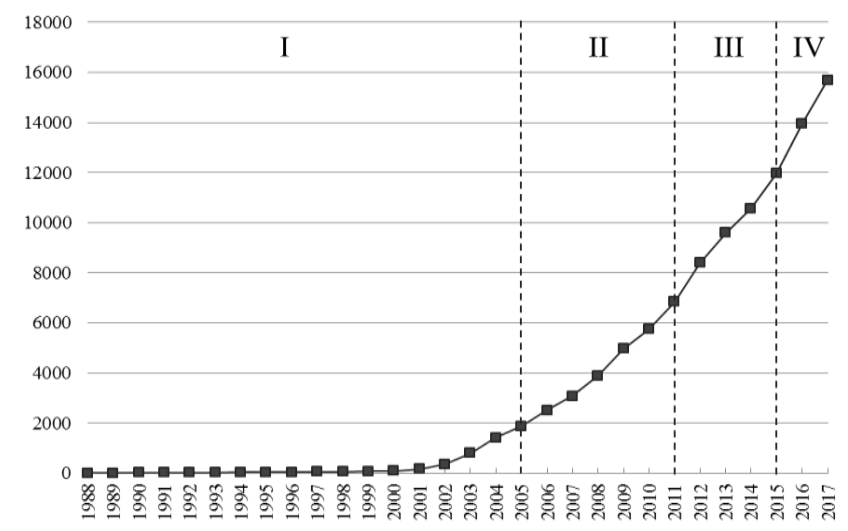

Fig. 3. Evolutionary periods.

After the development of period I and period II, the number of valid patents has accumulated, and the technology trend of low power design enters a new period. Period III is the rapid growth period. The number of valid patents remains at a prominent level. Period IV is the sustainable growth period. The number of valid patents exceeds 15000 in 2017. At the same time, the growth rate of valid patents in this period remains at $12.4 \%$. It is necessary to mine the potential space deeply for technology development, carry out new product development and file patent applications.

\section{CONCLUSIONS}

Technology trend is analyzed quantitatively based on valid patents. The measurement index of technology trend is developed based on valid patents. Hierarchical clustering analysis is employed to classify the technology trend. The methods are employed to measure the technology trend and analyze the trend with the data of long-term time series. The trend of low power design is analyzed quantitatively. The result of time series analysis shows that low power design went through the germination period, outbreak period, and rapid growth period, and is in the sustainable growth period at present. Thus, low power design could be one of the important directions for smartphone industry.

\section{CONFLICT OF INTEREST}

The authors declare no conflict of interest.

\section{AUTHOR CONTRIBUTIONS}

Mier Zhang conducted the research; Haipeng Li wrote the paper; Ximei Liu collected the data; all authors had approved the final version.

\section{REFERENCES}

[1] Q. Han and D. Cho, "Characterizing the technological evolution of smartphones: insights from performance benchmarks," in Proc. 18th Annual International Conference on Electronic Commerce: e-Commerce in Smart connected World, Suwon, Korea, August 17-19, 2016.

[2] The International Data Corporation. (2018). [Online]. Available: https://www.idc.com/getdoc.jsp?containerId=prUS43591418

[3] C. R. Panigrahi, B. Pati, M. Tiwary, and J. L. Sarkar, "EEOA: Improving energy efficiency of mobile cloudlets using efficient offloading approach," presented at 2015 IEEE International Conference on Advanced Networks and Telecommuncations Systems (ANTS), Kolkata, India, December 15-18, 2015.

[4] I. M. Taylor and M. A. Labrador, "Improving the energy consumption in mobile phones by filtering noisy GPS fixes with modified Kalman filters," in Proc. 2011 IEEE Wireless Communications and Networking Conference, Cancun, Mexico, March 28-31, 2011.

[5] Y. Xiao, R. Bhaumik, Z. Yang, M. Siekkinen, P. Savolainen, and A. Yla-Jaaski, "A system-level model for runtime power estimation on mobile devices," in Proc. 2010 IEEE/ACM Int'l Conference on Green Computing and Communications \& Int'l Conference on Cyber, Physical and Social Computing, Hangzhou, China, December 18-20, 2010.

[6] M. S. Elghazal, S. A. Younis, and M. S. Musbah, "Applying location based services for reducing mobile power consumption," in Proc. 2017 International Conference on Engineering and Technology (ICET), Antalya, Turkey, August 21-23, 2017.

[7] X. Hu, C. Zou, C. Zhang, and Y. Li, "Technological developments in batteries: a survey of principal roles, types, and management needs," IEEE Power and Energy Magazine, vol. 15, no. 5, pp. 20-31, August 2017.

[8] L. Iftode, C. Borcea, N. Ravi, P. Kang, and P. Zhou, "Smart phone: An embedded system for universal interactions," in Proc. 10th IEEE International Workshop on Future Trends of Distributed Computing Systems, Suzhou, China, May 28, 2004.

[9] D. N. Rakhmatov and S. B. K. Vrudhula, "An analytical high-level battery model for use in energy management of portable electronic systems," in Proc. 2001 IEEE/ACM International Conference on Computer-Aided Design, California, November 04-08, 2001.

[10] F. A. Ali, P. Simoens, T. Verbelen, P. Demeester, and B. Dhoedta, "Mobile device power models for energy efficient dynamic offloading at runtime," Journal of Systems and Software, vol. 113, pp. 173-187, March 2016.

[11] S. Li and S. Mishra, "Optimizing power consumption in multicore smartphones," Journal of Parallel and Distributed Computing, vol. 95, pp. 124-137, September 2016. 
[12] C. Choi and Y. Park, "Monitoring the organic structure of technology based on the patent development paths," Technological Forecasting and Social Change, vol. 76, no. 6, pp. 754-758, July 2009.

[13] S. B. Chang, K. K. Lai, and S. M. Chang, "Exploring technology diffusion and classification of business methods: Using the patent citation network," Technological Forecasting and Social Change, vol. 76, no. 1, pp. 107-114, January 2009.

[14] R. Kapoor and J. M. Lee, "Coordinating and competing in ecosystems: How organizational forms shape new technology investments," Strategic Management Journal, vol. 34, no. 3, pp. 274-296, July 2013.

[15] S. Altuntas, T. Dereli, and A. Kusiak, "Forecasting technology success based on patent data," Technological Forecasting and Social Change, vol. 96 , pp. 202-214, July 2015.

[16] K. Suzuki, J. Sakata, and J. Hosoya, "An empirical analysis on progress of technology fusion," 2008 Third International Conference on Digital Information Management, London, UK, November 13-16, 2008.

[17] S. Jun and S. J. Lee, "Emerging technology forecasting using new patent information analysis," International Journal of Software Engineering and Its Applications, vol. 6, no. 3, pp. 107-116, July 2012

[18] L. Gao, A. L. Porter, J. Wang, S. Fang, X. Zhang, T. Ma et al. "Technology life cycle analysis method based on patent documents," Technological Forecasting and Social Change, vol. 80, no. 3, pp. 398-407, March 2013.

[19] Y. H. Tseng, C. J. Lin, and Y. I. Lin, "Text mining techniques for patent analysis," Information Processing \& Management, vol. 43, no. 5, pp. 1216-1247, September 2007.

[20] Y. H. Chen, C. Y. Chen, and S. C. Lee, "Technology forecasting of new clean energy: The example of hydrogen energy and fuel cell," African Journal of Business Management, vol. 4, no. 7, pp. 1372-1380, July 2010.

[21] B. Yoon and Y. Park, "A text-mining-based patent network: Analytical tool for high-technology trend," The Journal of High Technology Management Research, vol. 15, no. 1, pp. 37-50, February 2004.

[22] S. Altuntas, T. Dereli, and A. Kusiak, "Analysis of patent documents with weighted association rules," Technological Forecasting and Social Change, vol. 92, pp. 249-262, March 2015.

[23] K. Liu, J. Arthurs, and R. Alexander, "Internal sequential innovations: How does interrelatedness affect patent renewal?" Research Policy, vol. 37, no. 5, pp. 946-953, June 2008.
[24] C. Grönqvist, "The private value of patents by patent characteristics: Evidence from Finland," The Journal of Technology Transfer, vol. 34, no. 2, pp. 159-168, April 2009.

[25] A. M. Clark and H. Berven. "The face of the patent is not the 'Whole Story': Determining effective life of a pharmaceutical patent in the United States," World Patent Information, vol. 26, no. 4, pp. 283-295, December 2004.

[26] R. Svensson, "Commercialization, renewal, and quality of patents," Economics of Innovation and New Technology, vol. 21, no. 2, pp. 175-201, May 2012

[27] Y. Deng, "Private value of European patents," European Economic Review, vol. 51, no. 7, pp. 1785-1812, October 2007.

[28] C. Luan, Z. Liu, and X. Wang, "Divergence and convergence: Technology-relatedness evolution in solar energy industry," Scientometrics, vol. 97, no. 2, pp. 461-475, November 2013.

[29] Y. G. Kim, J. H. Suh, and S. C. Park, "Visualization of patent analysis for emerging technology," Expert Systems with Applications, vol. 34, no. 3, pp. 1804-1812, April 2008

[30] S. Rani and G. Sikka, "Recent techniques of clustering of time series data: A survey," International Journal of Computer Applications, vol. 52, no. 15, pp. 1-9, August 2012.

Copyright $(92020$ by the authors. This is an open access article distributed under the Creative Commons Attribution License which permits unrestricted use, distribution, and reproduction in any medium, provided the original work is properly cited (CC BY 4.0).

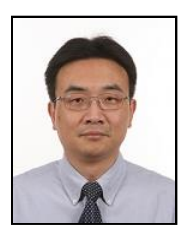

Mier Zhang graduated from Dalian University of Technology and incepted the doctor's degree in technical economics and management in 2002.

$\mathrm{He}$ is a professor in School of Economics and Management, Dalian University of Technology, with interest in technological economics, patent operation, and management of technology.

Prof. Zhang is the vice director of Center for S\&T Innovation and Entrepreneurship in Dalian University of Technology, vice secretary general of Chinese Society of Technology Economics, and associate editor-in-chief of Journal of Science Technology and Industry (in Chinese). 